\title{
Double Balloon Enteroscopy in a Pregnant Woman with Peutz-Jeghers Syndrome
}

\author{
Mesut Akarsu ${ }^{1}$, Soner Onem ${ }^{1}$, Zarni Htway ${ }^{1}$, Ozan Cengiz ${ }^{1}$, Suleyman Dolu ${ }^{1}$ and Leyla lyilikci ${ }^{2}$ \\ ${ }^{1}$ Department of Gastroenterology, Dokuz Eylul University School of Medicine, Izmir, Turkey \\ ${ }^{2}$ Department of Anaesthesiology and Reanimation, Dokuz Eylul University School of Medicine, Izmir, Turkey
}

\begin{abstract}
Peutz-Jeghers syndrome is an autosomal dominant disorder characterised by multiple hamartomatous polyps and muco-cutaneous pigmentation. Most polyps are found in the small intestine, especially in the jejunum. Enteroscopy with polypectomy is a reliable method to prevent polyp-related complications. A pregnant woman, who was diagnosed as a case of Peutz-Jeghers syndrome with a history of intestinal resection, was admitted to our clinic. Termination was recommended to the patient due to the possibility of polyps, causing obstruction during pregnancy. She underwent double balloon enteroscopy in the second trimester. Large polyps that could cause intussusception were removed and post-polypectomy bleeding was successfully controlled. This procedure was the first double balloon enteroscopy during pregnancy, reported in the literature. The procedure should be performed by experienced endoscopists, who can cope well with the complications in expert centres, as the procedure carries a high risk.
\end{abstract}

Key Words: Double baloon enteroscopy, Pregnancy, Peutz-Jeghers syndrome, Polyps.

How to cite this article: Akarsu M, Onem S, Htway Z, Cengiz O, Dolu S, Iyilikci L. Double Balloon Enteroscopy in a Pregnant Woman with Peutz-Jeghers Syndrome. J Coll Physicians Surg Pak 2022; 32(01):99-101.

\section{INTRODUCTION}

Endoscopic procedures such as gastroscopy, colonoscopy and endoscopic retrograde cholangiopancreatography (ERCP) during pregnancy are usually postponened till after delivery, except for urgent indications like bleeding, severe dyspepsia, cholangitis, or mass suspicion. The procedures have risks of induction of premature labour, teratogenesis from medications, placental abruption, cardiac arrhythmias and hypoxia. ${ }^{1}$ Therefore, the clinicians should consider medical and legal risks. Gastroscopy, colonoscopy, and ERCP procedures, performed during pregnancy, have been reported. ${ }^{2,3}$ However, double balloon enteroscopy (DBE) during pregnancy has not been reported in the literature yet. Here, we present succesful DBE which was performed in a pregnant woman with Peutz-Jeghers syndrome (PJS), due to the risk of intussusception.

\section{CASE REPORT}

A 22-year female patient, with PJS and a history of small bowel resection due to intussusception, presented to Gastroenterology Outpatient Clinic at $16^{\text {th }}$ week of herfirst pregnancy.

Correspondence to: Dr. Soner Onem, Department of

Gastroenterology, Dokuz Eylul University School of

Medicine, Izmir, Turkey

E-mail: soneronem@hotmail.com

Received: June 20, 2020; Revised: August 18, 2020;

Accepted: December 14, 2020

DOI: https://doi.org/10.29271/jcpsp.2022.01.99
Due to the previous history of invagination-related bowel resection, pregnancy termination was recommended by general surgery, considering that the pregnancy would increase the risk of bowel obstruction. Hence, the patient was informed of the risks of the procedure, and consent was obtained. The patient decided to carry on with her pregnancy. A DBE appointment was fixed in the second trimester of pregnancy. The procedure was carried out by a team including an endoscopist and an anesthesiologist, who had vast experience in endoscopic procedures during pregnancy. The patient was fully monitored during the procedure, and heart rate of the baby was closely observed. The patient underwent sedoanalgesia for the procedure. We performed DBE at $16^{\text {th }}$ week of gestation. Oral enteroscopy was advanced to proximal ileum, and eight polyps of approximately 1 to $4 \mathrm{~cm}$ in size were removed. After adrenaline was injected into the base of one of the short peduncle polyps and the polyp was removed, oozing of blood occurred from the site (Figures 1 and 2). Lauromacrogol 400 was injected into the bleeding site, and two hemoclips were deployed. As the bleeding continued, loop was applied and then hemostasis was achieved. At the end of uneventful pregnancy, a term baby boy of $3,850 \mathrm{~g}$ weight and $52 \mathrm{~cm}$ height was delivered vaginally. The baby is now of 3 years and is leading a healthy life.

\section{DISCUSSION}

PJS is an autosomal dominant disorder, characterised by multiple hamartomatous polyps and muco-cutaneous pigmentation. Most polyps are found in the small intestine, especially in the jejunum. Polyp-related complications are bleeding, intestinal obstruction and intussusception. 


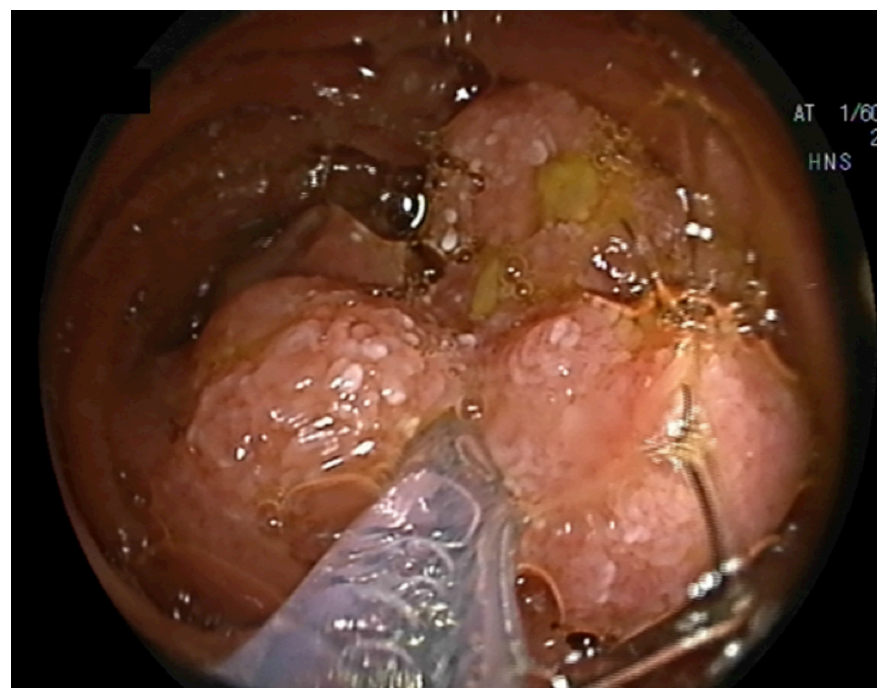

Figure 1: After holding the polyp with snare.

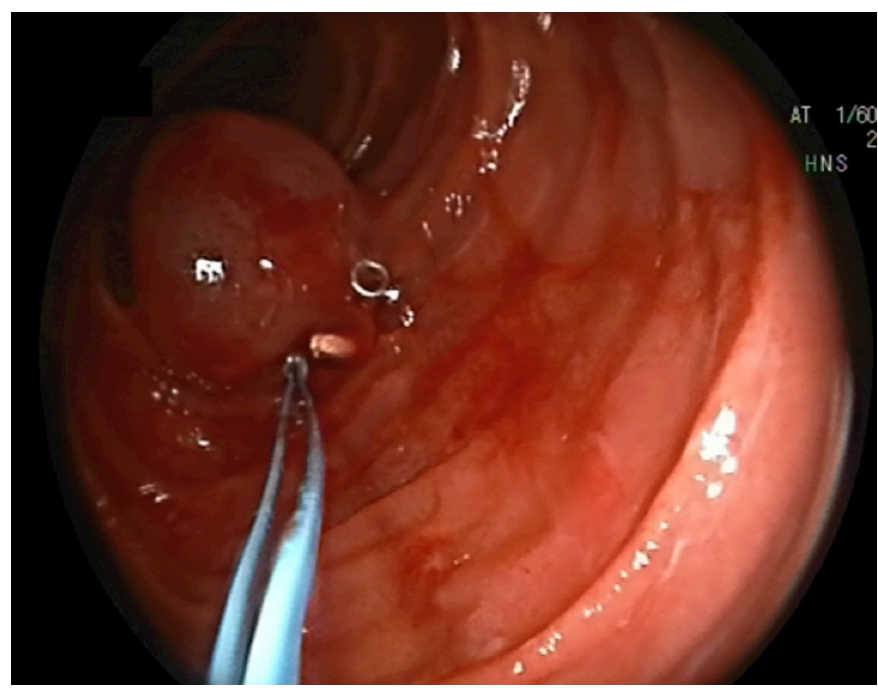

Figure 2: Loop and hemoclips applied to stop bleeding .

Around $45 \%$ of PJS patients had a history of at least one episode of intestinal obstruction. ${ }^{4}$ Adenoma and cancer may develop in PJS polyps (in up to $30 \%$ of polyps $>20 \mathrm{~mm}$ in diameter). ${ }^{5}$ Enteroscopy with polypectomy is a reliable method to prevent polyp-related complications ${ }^{6,7}$ Screeningenteroscopy is recommended for patients with a diagnosis of PJS at intervals of 1-3 years. ${ }^{8}$ More than 1,000 DBE procedures have been carried out in ourcentre. Endoscopists, who perform 50-100 diagnostic and therapeutic procedures per year, are accepted as experienced. ${ }^{9}$ Hence, our Department qualifies as an expert centre in this aspect. Around 15 PJS patients are in our follow-up programmes. The patients undergo DBE once every 2-3 years, and polyps more than one centimeter in size are removed efficiently. There is no experience with DBE during pregnancy to our knowledge. Cases of urgent cesarean delivery and emergency surgery due to intussusception have been reported during pregnancy. ${ }^{10}$ The procedure may be complicated by narrowing of the intestinal lumen due to compression by the enlarged uterus and changing anatomy in pregnant patients or peritoneal adhesions in patients with a history of abdominal surgery. The most common complication of enteroscopy in patients with PJS is bleeding, which is seen in approximately $4 \%$ cases. ${ }^{7}$ Therefore, the procedure should beperformed by experienced endoscopists, who can cope well with the complications, in expert centres, where appropriate equipment (hemoclips, adrenaline, cyanoacrylate, lauromacrogol, endoloops, etc.) are readily available. Otherwise, the procedure carries a high risk. Deep enteroscopy during pregnancy, including single or DBE, has not been reported in the literature. This is the first reported case in the literature, which underwent oral enteroscopy during pregnancy.

\section{PATIENT'S CONSENT:}

An informed consent form was obtained from the patient for the publication of the case.

\section{CONFLICT OF INTEREST:}

The authors declared no conflict of interest.

\section{AUTHORS' CONTRIBUTION:}

MA: Performed the enteroscopy, and edited and critically reviewed the manuscript.

SO: Collected data and wrote the manuscript.

$\mathrm{ZH}$ : Designing of the work.

OC: Drafting and analysis.

SD: Literature review.

LI: Performed the anesthesia.

\section{REFERENCES}

1. Cappell MS. The fetal safety and clinical efficacy of gastrointestinal endoscopy during pregnancy. Gastroenterol Clin North Am 2003; 32(1):123-79. doi:10.1016/S0889-8553 (02)00137-1.

2. Shergill AK, Ben-Menachem T, Chandrasekhara V. Guidelines for endoscopy in pregnant and lactating women. Gastrointest Endosc 2012; 76(1):18-24. doi:10.1016/j.gie. 2012.02.029.

3. O'Mahony S. Endoscopy in pregnancy. Best Pract Res Clin Gastroenterol 2007; 21(5):893-9. doi:10.1016/j.bpg. 2007.05.007.

4. Wu B-D, Wong Y-J, Fan L-L, Huang $H$, Zhou P, Yang $M$, et al. Clinical and Genetic analyses of 38 chinese patients with peutz-jeghers syndrome. Biomed Res Int 2020; 2020: 9159315. doi:10.1155/2020/9159315.

5. Yamamoto $\mathrm{H}$, Ogata $\mathrm{H}$, Matsumoto $\mathrm{T}$. Clinical practice guideline for enteroscopy. Dig Endosc 2017; 29(5): 519-46. doi:10.1111/den.12883.

6. Kopacova M, Tacheci I, Rejchrt S, Bures J. Peutz-Jeghers syndrome: Diagnostic and therapeutic approach. World J Gastroenterol 2009; 15(43):5397-408. doi:10.3748/ wjg.15.5397.

7. Wang YX, Bian DJ, Zhu HY, Dong YH, Fang AQ, et al. The role of double-balloon enteroscopy in reducing the maximum size of polyps in patients with Peutz-Jeghers syndrome: 12-year experience. J Dig Dis 2019; 20(8): 415-20. doi:10.1111/1751-2980. 12784.

8. Van Leerdam ME, Roos VH, Van Hooft JE. Endoscopic management of polyposis syndromes: European society of gastrointestinal endoscopy (ESGE) guideline. Endoscopy 
2019; 51(9):877-95. doi:10.1055/a-0965-0605.

9. Spada C, McNamara D, Despott EJ. Performance measures for small-bowel endoscopy: A European society of gastrointestinal endoscopy (ESGE) quality improvement initiative. Endoscopy 2019; 51(6):574-98. doi:10.1055/ a-0889-9586.

10. Li Z, Song M, Jiang H, Zhou Y. Peutz-Jeghers syndrome complicated with intussusception in late pregnancy. Lancet Oncol 2019; 20(12):e729. doi:10.1016/S1470-2045(19) 30692-8. 